\title{
Üstün Yetenekliler Alanında Yapılmış Tezlerin Analizi
}

\section{Analysis of Theses in the Field of Gifted and Talented}

\section{Servet KARDEŞ**}

\author{
Berrin AKMAN ${ }^{* * *}$
}

\section{Dila Nur YAZICI****}

Received: 15 November 2017

Accepted: 16 March 2018

\begin{abstract}
The studies on the subjects related to gifted students in the thesis studies in our country started at the beginning of 1990s and the number of thesis studies in this field has increased recently. In this research, 128 doctoral dissertations and master's theses which are made in the field of gifted students and are registered in YÖK (National Thesis Center) database between 1990-2016 were investigated. This research aims to make a comparative analysis of these theses made in the field of gifted students. This research was designed as a qualitative study. Data were analyzed by content analysis technique. Research questions are about the thesis's publication university and department, publication year, its method and subject matter. According to the results of the research, Gazi, Hacettepe and Karadeniz Teknik Universities are the pioneers in publishing these theses. These theses are usually from the fields of education, psychology and special education. Quantitative research method is generally used in these theses. In the theses, BILLSEMs are used extensively, the studies mainly focus on the primary and secondary school education and they are usually conducted with students as sample. The dissemination of thesis studies on gifted students at education levels apart from elementary and secondary school, studying in disciplines other than education and psychology, and increasing the thesis studies for diagnosis and model development are among the suggestions.
\end{abstract}

Keywords: gifted, master thesis, doctorate thesis.

ÖZ: Ülkemizde üstün yeteneklilerle ilgili konuların, tez çalışmalarında araştırılmasına yönelik çalışmalara 1990’lı yılların başlarında başlanılmış günümüzde ise bu alanda yapılan lisansüstü tezler artış göstermiştir. Üstün yetenekliler alanında yapılan ve 1990-2016 yılları arasında bulunan, YÖK(Ulusal Tez Merkezi) veri tabanında kayıtlı olan tezlerin incelenmesine yönelik olarak yapılan bu araştırmada 128 doktora ve yüksek lisans tezi incelenmiştir. Bu araştırma üstün yetenekliler alanında yapılan bu tezlerin karşılaştırmalı analizini yapmayı amaçlamaktadır. Tezlerin analiz edilmesinde nitel araştırma yöntemlerinden belge/doküman incelemesi tekniği kullanılmıştır. Araştırmanın verileri içerik analizi tekniği ile analiz edilmiştir. Tezlerin hangi üniversitelerden ve hangi bölümlerden çıktığı, kaç yılında basıldığı, yöntemi ve konusu gibi bilgiler araştırmanın bulgularını oluşturmaktadır. Araştırma sonuçlarına göre bu tezlerin yayınlanmasında Gazi, Hacettepe ve Karadeniz Teknik Üniversite'lerinin öncü olduğu, tezlerin genellikle eğitim öğretim, psikoloji ve özel eğitim alanlarından çıktığı, yöntem olarak genelde nicel araştırma yönteminin benimsendiği, yapılan çalışmalarda BILSEM'lerin yoğun kullanıldığı, çalışmaların daha çok ilkokul ve ortaokul kademesine odaklandığı ve örneklem olarak genelde öğrencilerle çalış1ldığ1 görülmüştür. Üstün yeteneklilerle ilgili tez çalışmalarının ilkokul ve ortaokul dışındaki eğitim kademelerine yaygınlaştırılması, eğitim ve psikoloji alanları dışındaki alanlarda da çalışılması, tanılama ve model geliştirmeye yönelik tez çalışmalarının arttırılması öneriler arasında yer almıştır.

Anahtar kelimeler: üstün yetenekli, yüksek lisans tezi, doktora tezi.

* This manuscript was presented as an oral presentation in International Talented And Gifted Conference: New Approaches and Educational Practices (4-5 May, 2017) at Gazi University.

** Corresponding Author: Res. Ass., Hacettepe University, Ankara, Turkey, kardesservet@gmail.com

**** Prof, Dr., Hacettepe University, Ankara, Turkey, bakman@ hacettepe.edu.tr

**** Res. Ass., Hacettepe University, Ankara, Turkey, yazcdila@gmail.com

\section{Citation Information}

Kardeş, S., Akman, B., \& Yazıcı, D. N. (2018). Üstün yetenekliler alanında yapılmış tezlerin analizi. Kuramsal Eğitimbilim Dergisi [Journal of Theoretical Educational Science],11(3), 411-430. 


\section{Giriş}

Üstün yetenekli çocuk tanımı ile ilgili birçok görüş ileri sürülmesine karşın, günümüzde hala ortak bir tanıma rastlamak güçtür. Stanford-Binet IQ testinin yaratıcısı ve aynı zamanda Amerika'da üstün yetenekliler ve onların özellikleri üzerinde en uzun süre boylamsal araştırmalar yapmış olan Terman, zekayı genel faktör olarak kabul etmektedir (Terman, 1921). Zeka bireyin üst düzey performansının karmaşık dinamiklerinin parçası olarak ifade edilebilir ve bilişsel gelişim sürecinin bir parçası olarak görülür (Freeman, 2004).

Thurstone ve Gardner gibi psikologlar ise zekanın bir çok boyutu olduğunu ifade ederler. Bu psikologlar zekayı, bütünsel olarak ölçmek için var olan ölçme araçları ile değerlendirmek yerine, bireysel yaratıcı düşünmenin merkezinde yer alan karar verme becerisinin zeka ile ilişkili önemli bir bileşen olduğunu ileri sürmektedirler (Gardner, 2011; Thurstone, 2013).

Renzulli (1986) ise üstün yetenekli bireylerin birbiriyle ilişkili üç alanda akranlarına göre üstün performans sergilediklerini belirtmiştir. Bireyin genel ve özel yeteneği, yaratıcılığ 1 ve bir işteki motivasyonu bireyin üstün yetenekliliğinde belirleyici faktörlerdir. Genel yeteneklere örnek olarak sözel sayısal yetenek, soyut düşünce, hafıza ve dilde akıcılık verilebilir. Özel yetenekler ise teknik alanlarda görülen; müzik, tiyatro, fizik, kimya, matematik ve bilim alanlarında görülen yeteneklerdir. Motivasyon bireyin nitelikli bir iş alması, yaptığı işe yüksek düzeyde odaklanması ve işini iyi bir şekilde yapma becerisidir. Yaratıcılık ise yeni fikirlerin ortaya konulması ve bunların problem çözmede kullanılmasını ifade eder. Bireyin üstün yetenekli olarak ifade edilebilmesi için bütün bu alanlarda toplumun \%85'inden daha başarılı olması ya da bu alanların en az birinden toplumun \% 98'inden daha yüksek performans sergilemesi gerekmektedir.

Ülkemizde Milli Eğitim Bakanlığı'nın (MEB) resmi tanımına göre üstün yetenekli birey; "Zekâ, yaratıcılık, sanat, spor, liderlik kapasitesi veya özel akademik alanlarında akranlarına göre yüksek düzeyde performans gösteren bireydir” (Milli Eğitim Bakanlığı, 2009). Bir başka tanıma göre üstün yetenekli birey, özel yetenek alanlarında üstün performans gösteren ve alan uzmanları tarafından tanılanmış olan bireylere denir. $\mathrm{Bu}$ bireyler kendi potansiyellerini ortaya koymak ve topluma katkıda bulunmak için farklılaştırılmış bir eğitim programına ihtiyaç duyarlar (The Maryland Report, 1972).

Üstün yetenekliler akranlarına göre çok meraklı, sürekli soru soran, hızlı öğrenen ve kolayca hatırlayabilen bireylerdir (Ataman, 1998). Akranlarına göre dünyaya daha farklı bir pencereden bakarlar. Bir şeylerin nasıl çalıştığına dair kafa yorduklarında derin merakları onları zor çıkmazlara sokabilir. Yüksek bir enerjiye sahip olan üstün yetenekliler hem çok hassas hem de mükemmeliyetçi olabildikleri gibi bazı durumlarda çabuk sıkılabilmekte bazen de öfke nöbetleri gösterebilmektedirler (Smutny, Walker \& Meckstroth, 2000). Üstün yetenekli çocuklar hayal kurma, oyun oynama ihtiyac1 duyarlar. Bütün yaşlardaki bireylerle iletişime geçmek ve gündelik yaşamın bir parçası olma ihtiyacı hissederler (Farrall \& Henderson, 2015). Dolayısıyla çocuklara gündelik yaşam içerisinde, ihtiyaçlarına yönelik zengin uyarıcılı bir çevre sunulması önemlidir. Zengin uyarıcılı çevre çocuğun özerkliğini sağlayacak ve çocuğun yaratıcılık ve kritik düşünme becerilerini destekleyecektir (Hertzog, 2017). Psikolojik değişkenler üstün yetenekli bireyin yeteneğini ortaya koymasında etkilidir. Risk almaya isteklilik, zorlukların üstesinden gelme, eleştiriye açık olma, rekabet, motivasyon gibi faktörler 
bireyin yeteneğini daha da ileriye taşımada belirleyici faktörler olmaktadır. Bu nedenle psikososyal farkındalık ve yetenekler üstün yetenekli bireyin eğitiminde yer alan uzmanlar ve aileler tarafından dikkate alınmalıdır (Subotnik, Olszewski-Kubilius \& Worrell, 2011).

Freeman (1998) ise erken yıllarda üstün yetenekli bireylerin özelliklerini aşağıdaki gibi sıralar;

Parlak zeka: Üstün zekalı çocukların en belirgin özelliği parlak zekalı olmalarıdır. Örneğin sözcükleri ve dili çok iyi kullanma yeteneğine sahiptirler. Çoğu zaman çok küçük ayrıntılara dikkat ederler. Bazı fikirlerde sıradışı bağlantılar kurma yeteneğine sahiptirler.

Farkındalık: Küçük çocukların zihinleri bilgiyi almak ve emmek için sürekli açıktır. Bazen cümlenizi tamamlamadan anlatmak istediğinizi anlarlar. Başkalarının davranışlarını taklit eder ve deneyimleriyle çok hızlı öğrenirler. Bazen yaşına göre hayli büyük görünürler.

Öğrenme yeteneği: Öğrenmeye çok arzuludurlar. Hızlı anlarlar. Hafizaları çok güçlüdür. Her ortamda ve her koşulda zihinleri bilgiyi emer. TV'den, insanların konuşmalarından, öğretmenden ve diğer bütün kaynaklardan hızlı bir şekilde bilgi öğrenir ve bilgiyi içselleştirmeye çalışırlar (Heller, 2004).

Bağımsızlık: Okulun ilk günlerinde bile yeterli oldukları gözlenir ve oldukça bağımsız davranırlar. Diğer çocukların basit uğraşlarla ve basit etkinliklerle uğraştıklarını gördüklerinde şok yaşarlar. Bazıları kendileri için özel ilgi alanları ve uğraşlar bulurlar.

Üstün yetenekli çocuklar eğitim sistemimiz içerisinde risk altında bulunmaktadırlar (Levent, 2011). Üstün yeteneklilerin tanılanması ve eğitimleri konusunda müfredat ve program uygulamaları yetersiz kalmaktadır (VanTassel-Baska, 1986). Üstün yeteneklilerin eğitimi konusunda öğretmenlere yönelik yeterince eğitim verilmemekte ve bu konudaki hizmet içi eğitimlerde yok denecek kadar azdır (Gross, 1999). Okullar çocukların ihtiyacı olan akademik alanlarda kendilerini geliştirmeli, öğretmenlere eğitimler vermeli ve çocukların ihtiyaçlarına uygun müfredat geliştirmelidir. Bu yüzden derin bilgiye sahip ve teknik yeteneği olan öğretmenlere daha çok ihtiyaç vardır (Subotnik \& diğerleri, 2011). Üstün yetenekli bireylerin kendi akranlarından farklı öğrenme ihtiyaçları vardır. Özel eğitim programları ile bu bireylerin bütün potansiyellerini ortaya koymaları sağlanmalıdır. Bu çocukların iyi bir eğitim almaları için ilk adım doğru bir biçimde tanılanmalarıdır. Bir çocuk üstün yetenekli olarak tanılandığı zaman, okul çocuğa uygun eğitim programı, ortam ve materyal sağlamalıdır (Hodge, 2013).

Üstün yeteneklilere çeşitli eğitim uygulamaları ve politikaları ile destek verilmesinin iki temel nedeni ekonomik faktör ve eşitlik ilkesidir. Gelecek üretkenliği ve yaratıcılığı artan toplumların olacaktır. Ayrıca dezavantajlı grupların kendi potansiyellerini ortaya koyabilmeleri için desteklenmeleri gerekmektedir. Üstün yetenekli bireyler özel öğrenme ihtiyaçları nedeniyle dezavantajlı duruma gelebilmektedirler (Watters \& Diezmann, 2003). Üstün yetenekli bireyler diğer bireylerden daha farklı düşünüp öğrenmede farklı stratejiler kullanmaktadırlar. Bu öğrencilerin eğitiminde öz düzenleyici öğrenme stratejileri daha etkili ve daha sık 
kullanılmalıdır. Üstün yeteneklilerin eğitiminde gruplama, hızlandırma ve zenginleştirme en fazla kullanılan stratejilerdir (Freeman, 2004).

Yukarıda genel olarak üstün yeteneklileri, ihtiyaçlarını ve onlara yönelik uygulamaları konu alan alanyazın taraması ülkemizde üstün yeteneklilerle ilgili politikaları içeren çalışmaların az sayıda olduğu sonucuna götürmüştür (Levent, 2011). Özel Eğitim ve Rehberlik Hizmetleri Genel Müdürlüğü tarafindan hazırlanan, Üstün Yetenekli Bireyler Strateji ve Uygulama Planı (2013)'nda bu alandaki zayıflıklar; konuyla ilgili yeterince akademik çalışma olmaması, çocukların tanılanmasında problemler olması ve yeterince ölçme aracı olmaması olarak ifade edilmektedir. Bunun yanında üstün yetenekli bireylerin ihtiyacına uygun müfredatın sınırlı olması, bu alanın ihmal edilmesi ve üstün yetenekli çocukların eğitiminde yer alacak nitelikli öğretmenlerin olmaması da başka bir problem alanı olarak ifade edilmektedir (Metin \& Kangal, 2012; Sak, 2011). Alanda yapılan bu araştırmalar, sorunların politika belirleyicilerin gözünden görülmesine yardımcı olması açısından önemlidir. Bu araştırma ülkemizde üstün yeteneklilerle ilgili olarak lisansüstü düzeyde yapılan çalışmalara bütüncül bir bakış açısı sağlaması açısından önemlidir. Üstün yeteneklilerle ilgili yapılan lisansüstü tezlerin tarandığ bu araştırmada YÖK-Ulusal Tez Merkezi veri tabanında bulunan 1990-2016 yılları arasında üstün yetenekliler ile ilgili yapılmış olan yüksek lisans ve doktora tezleri incelenmiştir.

Bu kapsamda aşağıdaki sorulara yanıt aranmıştır.

1) Üstün yeteneklilerle ilgili tezlerin yayınlandıkları yıllara göre dağılımı nasıldir?

2) Üstün yeteneklilerle ilgili tezlerin alanlara göre dağılımı nasıldır?

3) Üstün yeteneklilerle ilgili tezlerin bölüm bazında konulara göre dağılımı nasildır?

4) Üstün yeteneklilerle ilgili tezlerin araştırma deseni ve ölçme araçlarına göre dağılımı nasıldır?

\section{Yöntem}

\section{Araștırma Deseni}

Tarama modelli nitel araştırma deseninde olan bu araştırmada ulusal tez merkezinde yer alan ve üstün yetenekliler alanında yapılmış lisansüstü tezler incelenmiştir. Nitel araştırmalar; gözlem, görüşme ve mülakat gibi veri toplama yöntemlerin kullanıldığı olguların ve olayların doğal ortamında gerçekçi ve bütüncül bir şekilde gözlendiği araştırma türüdür. Nitel araştırmalar araştırmacının deneyimleri, topladığı ve analiz ettiği bilgiler sonucu şekillenir (Creswell, 2012). Araştırma bulguları için nitel araştırma desenlerinden belge/doküman incelemesi tekniği kullanılmıştır. Belge/döküman analizi, araştırılması hedeflenen olgular hakkında bilgi içeren yazılı materyallerin incelenmesini içeren yöntemdir (Şimşek \& Yıldırım, 2011).

\section{Çalışma Grubu}

Araştırmanın çalışma grubuna, YÖK Ulusal Tez Merkezi veri tabanından 'Üstün yetenekli” arama kelimesi sonucu ulaşılan; 1990-2016 yılları arasında yayınlanmış 92'si yüksek lisans, 35'i doktora ve 1'i tıpta uzmanlık alanında yapılmış olan toplam 128 lisansüstü tez alınmıştır. Tezlerden 91'i erişime açık 37 tanesi ise erişime kapalıdır. Bu 
nedenle erişime kapalı olan 37 tezin sadece özet bölümleri incelenebilmiştir. YÖK Ulusal Tez Merkezi verilerine göre 1990 yllından önce üstün yetenekliler alanında yapılan tez bulunmamaktadır. YÖK Ulusal Tez Merkezi'ne kayıtlı tezler 07.03.2017 30.04.2017 tarihleri arasında, araştırmacılar tarafından belirlenen kategorilere göre incelenmiştir.

\section{Verilerin Analizi}

Araştırmada ulaşılan tezler içerik analizi yöntemi kullanılarak incelenmiştir. Nitel araştırmalarda içerik analizi, insan davranışlarını ve yönelimlerini dolaylı yollarla ortaya çıkaran, yazılı araştırma dokümanlarını belirli kodlamalarla, sistematik bir şekilde ortaya koyan bir tekniktir (Fraenkel, Wallen \& Hyun, 2012) İçerik analizinde elde edilen veriler daha önceden belirlenen başliklar altında özetlenir ve yorumlanır (Yıldırım \& Şimşek, 2011). Bu süreçte 128 tez; türü, yayınlandığı yıl, üniversite ve eğitim alanlarına göre dağılımı, hangi eğitim kademesinde uygulandığı, konu dağılımları ve araştırma desenlerine göre incelenmiştir. Çalışmada içerik analizi süreci birebir izlenmiştir. Önce verilere ulaşılmış ve hazır hale getirilmiştir. Daha sonra analiz birimi tanımlanmış, kodlama şemaları ve kategoriler geliştirilmiştir. Kategori ve tema tanımlamaları yapılmış ve sonuçlar rapor edilmiştir (Tavşancıl \& Aslan, 2001). 


\section{Bulgular}

Türkiye'de üstün yetenekliler alanında yapılan tezlerin incelenmesi amaciyla yapılan bu araştırmada tezlerle ilgili bilgilerin dağılımları Tablo 1 ve Tablo 8 arasında verilmiştir. Tezlerin yayınlandığı yıllara ilişkin bulguları aşağıda Tablo 1'de verilmiştir.

\section{Tablo 1}

Tezlerin Yayınlandı̆̆ı Yıllara Göre Dă̆̆lımı

\begin{tabular}{|c|c|c|c|c|c|}
\hline Tezlerin Yayınlanma Yılı & $\begin{array}{c}\text { Tipta } \\
\text { Uzmanlık }\end{array}$ & $\begin{array}{l}\text { Yüksek } \\
\text { Lisans }\end{array}$ & Doktora & $\begin{array}{c}\text { Toplam } \\
f\end{array}$ & $\%$ \\
\hline 1990 & - & 1 & - & 1 & 0.78 \\
\hline 1995 & & 3 & - & 3 & 2.34 \\
\hline 1997 & & 1 & - & 1 & 0.78 \\
\hline 1998 & & 1 & - & 1 & 0.78 \\
\hline 2000 & & 1 & - & 1 & 0.78 \\
\hline 2001 & & 1 & - & 1 & 0.78 \\
\hline 2002 & & 2 & 2 & 4 & 3.13 \\
\hline 2003 & & 2 & - & 2 & 1.56 \\
\hline 2004 & & 1 & 1 & 2 & 1.56 \\
\hline 2005 & & 2 & - & 2 & 1.56 \\
\hline 2006 & & 2 & 2 & 4 & 3.13 \\
\hline 2007 & & 5 & 1 & 6 & 4.69 \\
\hline 2008 & & 2 & - & 2 & 1.56 \\
\hline 2009 & & 4 & - & 4 & 3.13 \\
\hline 2010 & & 12 & 4 & 16 & 12.5 \\
\hline 2011 & & 5 & 3 & 8 & 6.25 \\
\hline 2012 & 1 & 5 & 3 & 9 & 7.03 \\
\hline 2013 & & 5 & 2 & 7 & 5.47 \\
\hline 2014 & & 11 & 4 & 15 & 11.72 \\
\hline 2015 & & 16 & 5 & 21 & 16.41 \\
\hline 2016 & & 9 & 9 & 18 & 14.06 \\
\hline Toplam & & & & 128 & 100 \\
\hline
\end{tabular}

Tablo 1'de tezlerin yayınlandıkları yıllara göre dağılımına bakıldığında üstün yetenekliler alanında ilk tezin 1990 yılında yazıldı̆̆ 1 , 1990-2001 yılları arasında ise 8 (\%6.25) adet tez yapıldığı ve bu yıllar arasında yazılan bütün tezlerin yüksek lisans düzeyinde yazılmış olduğu görülmektedir. Üstün yetenekliler alanında ilk doktora tezinin 2002-2005 yılları arasında yazıldığı görülmektedir. Bu dönemde 3’ü doktora tezi olmak üzere toplam 10 (\%7.81) tez yapılmıştır. 2006-2008 yılları arasındaki süreçte 12 
(\%9.38) tez yapılmıştır. Bu yıllardan sonra üstün yetenekliler alanında yazılan tezlerin sayısında artış olduğu görülmektedir. 2009-2011 yılları arasında 28 (\%21.88) adet yüksek lisans ve doktora tezi yapılmıştır. 2012-2014 yılları arasında 31(\%24.22) tez yapılmış ve son iki yılda ise $39(\% 30.47)$ tez yapılmıştır. Son yıllarda üstün yetenekliler alanında yapılan çalışmaların sayısında bir artış olduğu görülmektedir. Özellikle son üç yılda bugüne kadar yapılan doktora tezi sayısı kadar doktora tezi yazılmıştır. Tezlerin yapıldığı üniversitelere göre dağılımları ise aşağıdaki tabloda verilmiştir.

Tablo 2

Tezlerin Yapıldı̆̆g Üniversiteye Göre Dă̆ılımı

\begin{tabular}{|c|c|c|c|c|}
\hline & $\begin{array}{l}\text { Yüksek } \\
\text { lisans } f\end{array}$ & $\begin{array}{l}\text { Doktora } \\
f\end{array}$ & $\begin{array}{l}\text { Toplam } \\
f\end{array}$ & $\%$ \\
\hline Gazi Üniversitesi & 13 & 10 & 23 & 17.97 \\
\hline Hacettepe Üniversitesi & 8 & 4 & 12 & 9.38 \\
\hline Karadeniz Teknik Üniversitesi & 6 & 5 & 11 & 8.59 \\
\hline Dokuz Eylül Üniversitesi & 4 & 2 & 6 & 4.69 \\
\hline Ankara Üniversitesi & 3 & 2 & 5 & 3.91 \\
\hline Marmara Üniversitesi & 3 & 1 & 4 & 3.13 \\
\hline Sakarya Üniversitesi & 4 & - & 4 & 3.13 \\
\hline Yeditepe Üniversitesi & 4 & - & 4 & 3.13 \\
\hline İnönü Üniversitesi & 3 & 1 & 4 & 3.13 \\
\hline Boğaziçi Üniversitesi & 3 & - & 3 & 2.34 \\
\hline İstanbul Üniversitesi & - & 4 & 4 & 2.34 \\
\hline Abant İzzet Baysal Üniversitesi & 3 & - & 3 & 2.34 \\
\hline Gaziosmanpaşa Üniversitesi & 3 & - & 3 & 2.34 \\
\hline Anadolu Üniversitesi & 3 & - & 3 & 2.34 \\
\hline Yıldız Teknik Üniversitesi & 3 & - & 3 & 2.34 \\
\hline $\begin{array}{l}\text { Diğer üniversiteler (ODTÜ, Uludağ, Selçuk, Beykent, } \\
\text { Mustafa Kemal vs.) }\end{array}$ & 30 & 6 & 37 & 28.91 \\
\hline Toplam & 93 & 35 & 128 & 100 \\
\hline
\end{tabular}

Üstün yetenekliler alanında yazılan tezlerin üniversitelere göre dağılımına baktığımızda bu alanda en çok tezin 23 (\%17.97) tez ile Gazi Üniversite'sinde yapıldığı görülmektedir. Hacettepe Üniversitesi'nde 12 (\%9.38), Karadeniz Teknik Üniversitesi 'nde ise $11(\% 8.59)$ tane tez yapılmıştır. Yazılan tezlerin yaklaşık üçte birinin yani 40 ( \%31.26) tezin, Ankara'daki üniversitelerde yazıldığı görülmektedir. Dokuz Eylül Üniversitesi’nde 6 (\%4.69) Marmara, Sakarya, Yeditepe ve İnönü Üniversitesi'nde ise 
üstün yetenekliler alanında 4'er tez yazılmıştır. Boğaziçi, İstanbul, Abant İzzet Baysal, Gaziosmanpaşa ve Anadolu Üniversitelerinde, 3’er tez yazıldığg görülmektedir. Üniversitelerde yapılan tez çalışmalarının alanlara göre dağılımı aşağıdaki tabloda verilmiştir.

Tablo 3

Tezlerin Alanlara Göre Dă̆ılımı

\begin{tabular}{lll}
\hline Tezlerin Alanlara Göre Dağılımı & $f$ & $\%$ \\
\hline Eğitim ve Öğretim & 27 & 20.99 \\
Özel Eğitim & 15 & 11.72 \\
Psikoloji & 15 & 11.72 \\
Matematik & 13 & 10.16 \\
İlköğretim & 12 & 9.38 \\
Çocuk Gelişimi & 9 & 7.03 \\
Rehberlik & 7 & 5.47 \\
Okul Öncesi Eğitimi & 5 & 3.95 \\
Güzel Sanatlar & 5 & 3.95 \\
İşletme & 5 & 3.13 \\
Ev Ekonomisi & 4 & 3.13 \\
Dil Bilim & 4 & 2.34 \\
Bilim Teknoloji Bölümleri & 3 & 2.34 \\
Sosyoloji & 3 & 1.56 \\
Diğer (Müzik, Fizik, kimya, psikiyatri) & 2 & 3.13 \\
\hline Toplam & 4 & 100 \\
\hline
\end{tabular}

Üstün yetenekliler alanında yazılan tezlerin alanlara göre dağılımına baktığımızda, tezlerin genel olarak eğitim öğretim başlığı altında yoğunlaştığ1 görülmektedir. Eğitim Öğretim alanındaki (27; \%20.99) tezler, Eğitim Bilimleri Anabilim dalı, Eğitim Yönetimi ve Denetimi, Eğitim ve Teftiş, Eğitim Programları ve Öğretimi bilim dallarından çıkmıştır. Özel eğitim alanı (15; \%11.72) ve Psikoloji alanındaki (15; \%11.72) tezler bu alanda yapılan çalışmalarda ilk sıraları almaktadır. Özel eğitim Anabilim Dalından çıkan tezlerin 5'i üstün zekalıların eğitimi bilim dalında yazılmıştır. Matematik Anabilim dalında 13 (\%10.16) tez yazılmıştır. Üstün yetenekliler alanında en çok tezin yazıldığı anabilim dallarının İlköğretim (12; \%9.38), Çocuk Gelişimi (9; \%7.03), ve Rehberlik (7; \%5.47) olduğu görülmektedir. Okul öncesi eğitimi (5; \%3.95), Güzel Sanatlar (5; \%3.95) ve İşletme (4; \%3.13) bu konuda tezlerin 
üretildiği diğer bilim dallarıdır. Güzel sanatlar alanında yapılan tezlerin üstün yeteneklilerde sanat eğitimi konusunda olduğu görülmektedir. Müzik, fizik, kimya ve psikiyatri bölümlerinde de birer tez yazılmıştır. Tezlerin uygulandığı eğitim kurumları ve eğitim kademelerine göre dağılımları aşağıdaki tabloda görülmektedir.

Tablo 4

Tezlerin Uygulandığı Ĕ̆itim Kurumu ve Ĕ̆itim Kademesine Göre Dă̆ılımı

\begin{tabular}{lll}
\hline Eğitim Kurumu/Eğitim Kademesi & $f$ & $\%$ \\
\hline Okul Öncesi & 7 & 6.03 \\
İlkokul & 28 & 24.14 \\
Ortaokul & 56 & 48.28 \\
Lise & 24 & 20.69 \\
Üniversite & 1 & 0.86 \\
Toplam & 116 & 100 \\
BİLSEM'lerde uygulanan tezler & 49 & 42.24 \\
Normal eğitim kurumlarında uygulanan tezler & 67 & 57.76 \\
\hline Toplam & 116 & 100
\end{tabular}

Tablo 4 incelendiğinde tezlerin yarısına yakınının ortaokul eğitim kademesi (56; \%48.28)'nde uygulandığı görülmektedir. Tez çalışmalarının 28 (\%24.14)'i ilkokul kademesinde, 24 (\%20.69)'ü ise lise kademesinde yapılmıştır. Okul öncesi eğitim kademesi $(7 ; \% 6.03)$ ve üniversite kademesi $(1 ; \% 0.86)$ 'nde ise pek fazla tez çalışması yapılmadığı görülmüştür. Örgün eğitim kurumları (67; \%57.76) ve BİLSEM (49; \%42.24)'lerde yapılan çalıșmaların birbirine yakın olduğu ve BİLSEM'lerin üstün yeteneklilerle çalışma için kullanılan önemli merkezler olduğu görülmektedir. Tezlerin bölüm bazında konularına göre dağılımları aşağıdaki tabloda görülebilir. 


\section{Tablo 5}

\section{Tezlerin Bölüm Bazında Konulara Göre Dağılımları}

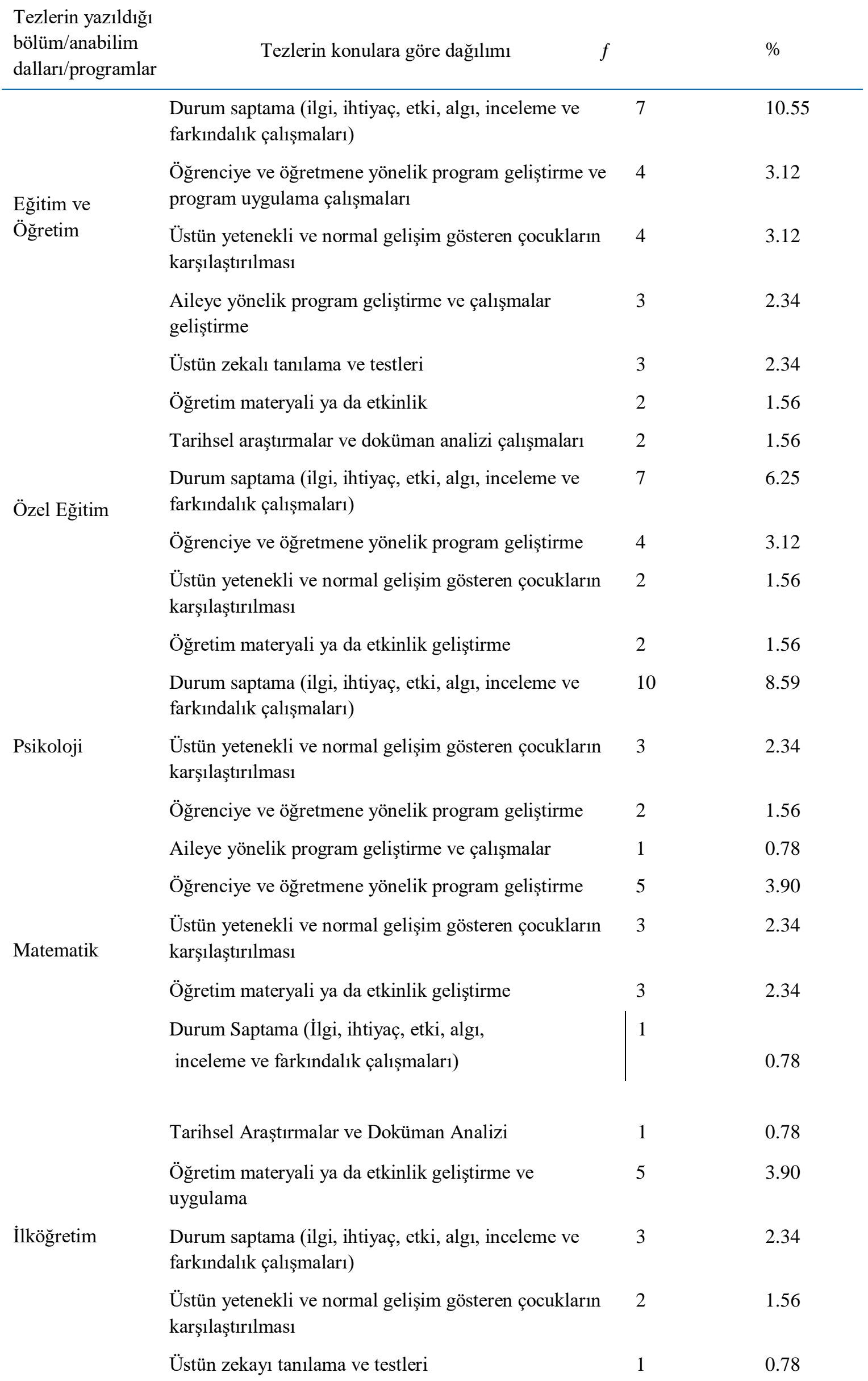


Tarihsel araştırmalar ve doküman analizi çalışmaları

Öğrenciye ve öğretmene yönelik program geliştirme

Çocuk Gelişimi

Durum saptama (ilgi, ihtiyaç, etki, alg1, inceleme ve

farkındalık çalışmaları)

Üstün yetenekli ve normal gelişim gösteren çocukların 2

karşılaştırılması

Üstün zekayı tanılama ve testleri

Durum saptama (ilgi, ihtiyaç, etki, alg1, inceleme ve farkındalık çalışmaları)

Rehberlik

Öğrenciye ve öğretmene yönelik program geliştirme

Üstün yetenekli ve normal gelişim gösteren çocukların $\quad 1$ karşılaştırılması

Aileye yönelik program geliştirme ve çalışmalar

Durum saptama (ilgi, ihtiyaç, etki, alg1, inceleme ve

Okul Öncesi farkındalık çalışmaları)

Eğitim

Üstün yetenekli ve normal gelişim gösteren çocukların karşılaştırılması

Üstün zekayı tanılama ve testleri

Durum saptama (ilgi, ihtiyaç, etki, algı, inceleme ve $\quad 4$

Güzel Sanatlar farkındalık çalışmaları)

Öğrenciye ve öğretmene yönelik program geliştirme

İşletme

Durum saptama (ilgi, ihtiyaç, etki, alg1, inceleme ve farkındalık çalışmaları)

Öğrenciye ve öğretmene yönelik program geliştirme $\quad 2 \quad 1.56$

Ev Ekonomisi

Durum saptama (ilgi, ihtiyaç, etki, alg1, inceleme ve farkındalık çalışmaları)

Üstün zekalı tanılama ve testleri

Diğer (Dil bilim,

Durum saptama (ilgi, ihtiyaç, etki, alg1, inceleme ve

Bilim Teknoloji, farkındalık çalışmaları)

Sosyoloji, Müzik, kimya,

Öğrenciye ve öğretmene yönelik program geliştirme fizik, psikiyatri)

Öğretim materyali ya da etkinlik geliştirme

Tarihsel araştırmalar ve doküman analizi çalışmaları

Tezlerin konulara göre dağılımına baktığımızda algı, durum tespiti, inceleme, etki gibi çalışmaları içeren durum saptama başlığı altında 43 (\%33.59) tezin yazıldığı görülmektedir. Bununla birlikte önemli oranda (23; \%17.97) tezin yapıldı̆̆ araştırma türü ise deneysel araştırmalardır. En çok çalışılan tez konusunun öğrenciye yönelik program geliştirme tezleri $(16 ; \% 12.5)$ olduğu görülmektedir. Üstün yetenekli ve normal gelişim gösteren çocukların karşılaştırılması yapılan 14 (\%10.94) tezle, araştırmacıların ilgi gösterdiği bir diğer konu olarak karşımıza çıkmaktadır. 
Öğretmenlerle yapılan çalışmalar $(9 ; \% 7.03)$ ve öğretim materyali ya da etkinlik geliştirme çalışmaları $(7 ; \% 5.47)$ tezlerde yer alan konulardır. Tezlerde en az tercih edilen konuların, Üstün zekayı tanılama ve testleri (5; \%3.91), Aileye Yönelik Program Geliştirme ve Çalışmalar (5; \%3.91), Tarihsel Araştırmalar ve Doküman Analizi Çalışmaları (5; \%3.91) ve Ölçek geliştirme ya da Uyarlama Çalışmaları (3; \%2.34) olduğu görülmektedir. Aşağıdaki tabloda tezlerin araştırma desenlerine göre dağılımı görülmektedir.

\section{Tablo 6}

Tezlerin Araştırma Desenlerine Göre Dă̆ılımı

\begin{tabular}{lll}
\hline Araştırma desenleri & $f$ & \% \\
\hline Nicel Araştırmalar & $\mathbf{8 4}$ & $\mathbf{6 5 . 6 3}$ \\
İlişkisel Tarama araştırmaları & 36 & 42.85 \\
Deneysel araştırmalar & 26 & 30.95 \\
Betimsel araştırmalar & 18 & 21.42 \\
Nedensel karşılaştırma araştırmaları & 2 & 2.38 \\
Tarihsel araştırmalar & 2 & 2.38 \\
Nitel araştırmalar & $\mathbf{2 6}$ & $\mathbf{2 0 . 3 1}$ \\
Örnek olay (case study) & 14 & 53.84 \\
Fenomenoloji araştırmaları & 4 & 15.38 \\
Belge/doküman incelemesi & 4 & 15.38 \\
Eylem araştırmaları & 2 & 7.69 \\
Gömülü teori araştırmaları & 2 & 7.69 \\
Karma desen araştırmaları & $\mathbf{1 8}$ & $\mathbf{1 4 . 0 6}$ \\
\hline Toplam & $\mathbf{1 2 8}$ & $\mathbf{1 0 0}$ \\
\hline
\end{tabular}

Tablo 6'ya baktığımızda yapılan tezlerde araştırma yöntemi olarak nicel araştırma (84; \%65.63) yönteminin en fazla tercih edilen yöntem olduğu görülmektedir. Nitel araştırma yöntemi (26; \%20.31) tezlerin beşte birini oluşturmakla birlikte son yıllarda yapılan Karma desendeki çalışmaların (18; \%14.06) sayısında önemli oranda artış olduğu görülmektedir. Üstün yetenekliler alanında yapılan tezlerin kullandıkları ölçme araçlarına göre dağılımları aşağıdaki tabloda görülmektedir. 
Tablo 7

Tezlerin Kullandıkları Ölçme Araçlarına Göre Dă̆ılımı

\begin{tabular}{lll}
\hline Tezlerde kullanılan ölçme araçları & $f$ & $\%$ \\
\hline Araştırmacı tarafından ölçme aracı geliştirilmiş tezler & 59 & 46.09 \\
Başkası tarafindan geliştirilen ölçme araçları kullanılmış tezler & 64 & 50.00 \\
Doküman incelemesi yapılan tezler & 5 & 3.91 \\
\hline Toplam & 128 & 100 \\
\hline
\end{tabular}

Tezlerde kullanılan ölçme araçlarına baktığımızda araştırmacıların yarısının (64; \%50.00) başkaları tarafından geliştirilen ölçme araçlarını kullandıkları, diğer araştırmacıların kendi ölçme araçlarını geliştirdikleri (59; \%46.09) ve bazı araştırmacıların ölçme aracı kullanmadan doküman analizi (5; \%3.91) yaptıkları görülmüştür. Bazı araştırmalarda araştırmacının hem kendi geliştirdiği ölçme aracını hem de başkaları tarafindan geliştirilen ölçme araçlarını kullandığı görülmektedir. Son olarak üstün yetenekliler alanında yapılan tezlerin örneklem büyüklüklerine göre dağılımları ise aşağıdaki tabloda görülmektedir.

Tablo 8

Tezlerin Örneklem Büyüklüklerine Göre Dă̆ılımları

\begin{tabular}{lll}
\hline Kişi Sayısi & $f$ & $\%$ \\
\hline 1 -20 kişi & 18 & 14.06 \\
$20-50$ kişi & 20 & 15.61 \\
$50-100$ kişi & 18 & 14.06 \\
$100-200$ kişi & 25 & 19.53 \\
$200-400$ kişi & 20 & 15.61 \\
400 ve üzeri kişi & 22 & 17.18 \\
Diğer(doküman analizi tezleri vb.) & 5 & 3.95 \\
\hline Toplam & 128 & 100 \\
\hline
\end{tabular}

Üstün yetenekliler alanında yapılan tezlerdeki örneklem büyüklüğüne dair bilgilere baktığımızda örneklem sayılarının tezlerde farklılaştığı görülmektedir. Az sayıda örneklemle çalışılan tezler olduğu gibi örneklem grubu oldukça geniş olan tezlerde bulunmaktadır. Tezlerde farklı büyüklüklerde örneklem ve çalışma gruplarının yer aldığı görülmektedir. 


\section{Sonuç ve Tartışma}

Milli Eğitim Bakanlığı tarafından "Zekâ, yaratıcılık, sanat, spor, liderlik kapasitesi veya özel akademik alanlarında akranlarına göre yüksek düzeyde performans gösteren birey" (MEB, 2009) olarak tanımlanan üstün yeteneklilerle ilgili çalışmalar ülkemizde artarak devam etmektedir. Bu araştırmada da ülkemizde üstün yetenekliler ile ilgili tezleri analiz etmek ve bu tezlerdeki çalışma konularını araştırmacıların dikkatine sunmak amaçlanmıştır. Araştırmanın bulguları incelendiğinde ülkemizde yapılan üstün yetenekliler alanındaki tezlerin yayınlanmasında büyük üniversitelerin öncü olduğu, tezlerin genellikle eğitim öğretim, psikoloji ve özel eğitim bilim alanlarında yapıldığı belirlenmiştir. Özellikle eğitim fakültelerinin lisansüstü eğitimlerinin belli başlı üniversitelerde ve belli bölümlerde olduğu göz önüne alındığında, üstün yeteneklilerle ilgili çalışmaların belli üniversitelerde yapılmış olması beklendik bir durumdur. Ölçme aracı olarak hem araştırmacı tarafından geliştirilmiş ölçekler hem de başkaları tarafından geliştirilen ölçeklerin kullanıldığı, yapılan araştırmalarda BİLSEM'lerin yoğun olarak kullanıldığı görülmüştür. Dağlığlu \& Suveren (2013)'de yaptıkları araştırmada, 1992 yılında BİLSEM'lerin kurulmasıyla birlikte üstün yetenekliler alanında yapılan çalışmaların yoğun artış gösterdiği sonucuna ulaşmışlardır. Araştırmada tez çalışmalarının daha çok ortaokul ve ilkokul kademesine odaklandığ1 ve okul öncesi dönemde yapılan tez çalışmalarının çok az olduğu görülmüştür. Benzer olarak Metin, Özbay \& Dağlığlu (2008) yaptıkları araştırmada okul öncesi eğitim çağındaki çocuklarla yapılan araştırmaların çok az olduğu sonucuna ulaşmışlardır. Üstün zekayı tanılamada, bireyin standart testlerde aldığı IQ puanlarına bakılmaktadır. Okul öncesi dönemde akademik becerilerin azlığı ve okul müfredatındaki kazanımların yetersizliği bu dönemde tanılamanın ve üstün yetenekliler eğitiminin zorluğu olarak ifade edilebilir (Dümenci, Gürsoy \& Aral, 2017). Bununla birlikte Kettler, Oveross \& Salman (2017) yaptıkları araştırmada okul öncesi eğitim kurumlarında üstün yetenekli çocuklara yönelik herhangi bir politika olmadığı, üstün yeteneklilere yönelik politika ve hizmetlerin öncelik oluşturmadığ ulaşmışlardır. Benzer olarak Cevher Kılıç (2015) yaptığı araştırmada Türkiye'de üstün yeteneklilere yönelik nitelikli ve kapsamlı bir eğitim politikası olmadığı sonucuna ulaşmıştır. Oysa bireyin kişiliğinin temellerinin atıldığı okul öncesi eğitim çağında üstün yeteneklilere yönelik çalışmaların arttırılması ve çocukların bu dönemde tanılanması oldukça önemlidir. Schreglmann (2016)'nın Türkiye'de Üstün Yetenekli Öğrenciler ile İlgili yapılan Yükseköğretim Tezlerinin İçerik Analizi (2010-2015) çalışmasının sonuçlarına baktığımızda araştırmacı BİLSEM'lerin yoğun olarak kullanıldığ 1 ve araştırmalarda benzer örneklemler seçildiği sonucuna ulaşmıştır. Özenç \& Özenç (2013)'in Türkiye'de üstün yetenekli öğrencilerle ilgili yapılan lisansüstü eğitim tezlerinin çok boyutlu olarak incelenmesi başlıklı çalışmasında ve Nacar (2015)'ın 2005-2014 yılları arasında üstün yeteneklilerin matematik eğitimi üzerine yapılan çalışmaları incelediği araştırmasının da bu araştırmanın sonuçlarıyla örtüşen nitelikte, tezlerin ilköğretim kademesinde ve BİLSEM'lerde çalışıldığ 1 ve tezlerin büyük çoğunluğunda nicel araştırma yöntemlerinin kullanıldığ 1 sonucuna ulaşılmıştır. Konu olarak üstün yeteneklilere yönelik algı, farkındalık, ihtiyaç ve özellikler ile ilgili çalışmalar en fazla çalışılan konular olmuştur. MEB Üstün Yetenekli Bireyler Strateji ve Uygulama Planı (2013)'nda üstün yeteneklilerin eğitimine yönelik farklılaştırılmış eğitim modellerinin ve programlarının olmaması zayıflık olarak ifade edilmiştir. Benzer 
şekilde Sak \& diğerleri (2015) yaptıkları araştırmada üstün yeteneklilere yönelik uygulamalar içeren kurumların standart bir programdan yoksun oldukları sonucuna ulaşmışlardır. $\mathrm{Bu}$ durum alanda program geliştirmeye dönük yapılan tezlerin yeterli olmadığı ya da bu konudaki tezlerden elde edilen sonuçların yaygınlaştırılmasının yeterince yapılmadığının göstergesi olabilir. Yine MEB Üstün Yetenekli Bireyler Strateji ve Uygulama Planı (2013)'nda farklı eğitim modellerini içeren akademik çalışma sayısının az olduğu vurgulanmıştır. Araştırmada son üç yılda bu alanda yapılan yüksek lisans ve doktora tezlerinde önemli artış olduğu görülmüştür. Bu artışta planın raporlarında ortaya koyulan sonuçların etkisi olduğu düşünülebilir. Üstün zekayı tanılama ve testleri, ailelere yönelik program geliştirme, ölçek geliştirme ve uyarlama çalışmaları ise en az çalışılan konular olmuştur. Araştırmayı destekler bir bulgu da Dağlıoğlu \& Suveren (2013)'in Türkiye'de üstün yeteneklilerin tanılanmasında geçerli ve güvenilir ölçme araçlarının yok denecek kadar az olduğunu ifade etmeleridir. Bir başka araştırmada Güçin (2014)'in “Türkiye'de üstün yetenekliler ve üstün zekâlılar alanında yapılmış akademik çalışmaların çeşitli değişkenler açısından incelenmesi”" çalışmasının sonuçları ise üstün yetenekliler alanında en fazla durum saptama çalışmalarının yapıldığı en düşük oranda ise üstün yetenekli bireyleri tanılama çalışmalarının yer aldığını ortaya koymaktadır. Ayrıca Cao, Jung \& Lee (2017) yaptıkları araştırmada üstün yeteneklileri değerlendirme çalışmalarının yeterli olmadığı sonucuna ulaşmışlardır.

Sonuç olarak yapılan tez çalışmalarında üstün yeteneklilerle ilgili tezlerde 2010 yılından itibaren bir artış olduğu, üstün yeteneklilerle ilgili en çok Gazi, Hacettepe ve Karadeniz Teknik Üniversite'lerinde çalışıldığı, genellikle eğitim ve psikoloji alanlarında bu konunun çalışıldığı sonucuna ulaşılmıştır. Ayrıca konu bazında üstün yetenekli bireyleri tanılama testleri ve program geliştirme çalışmalarına yeterince yer verilmediği görülmüştür. BİLSEM'lerde yoğun olarak çalışıldığı, tezlerin daha çok nicel olarak desenlendiği belirlenmiştir.

\section{Öneriler}

1. Üstün yetenekliler konusunun eğitim ve psikoloji dışında da farklı alanlar tarafından sıklıkla çalışılmaya başlanması,

2. Yaş gruplarının çalışılmasında erken çocukluk dönemindeki çocuklarla daha fazla çalışılmaya başlanması,

3. Üstün yetenekli bireylerin ihtiyaçlarını ortaya koyacak, farklı modellerin, yaklaşımların sunulduğu çalışmaların yapıılması,

4. Tez konuları belirlenirken MEB üstün yeteneklilere yönelik strateji planında yer alan, üstün yetenekli alanındaki ihtiyaçlara öncelik verilerek (tanılama, öğretmen eğitimi, müfredat vb) problem alanlarına da odaklanılması önerilebilir. 


\section{Summary}

Purpose and Significance: In order to reveal the social-emotional and physical development, intellectual and cultural properties of gifted individuals, their strengths, talents, interests and motivation should be known. At the same time, it can be said that the applied curriculum in the schools does not comply with the gifted and talented children' abilities (Riley, 2000). With differentiated learning experiences, new models and programs need to be developed for gifted students. While developing a program for gifted and talents, it is important to consider insufficient areas.

When we analyze the policies about gifted ones in our country, we can say that the studies about this subject are inadequate. The Strategy and Implementation Plan for Gifted Individuals (2013) express the deficiencies in this area as follows: There are not enough academic studies on the subject. There are problems in the diagnosis of gifted children and the measurement tools in this field are not enough. The lack of curriculum which is appropriate to the needs of gifted individuals and the lack of qualified teachers to take part in the training of gifted children are other deficiencies. So this report helps us to see the problems from the point of policymakers. We will have a chance to see how well the researchers focus on the problem areas mentioned above and they will contribute to these deficiencies or not.

Analyzing of the theses in this field is important in terms of how the thesis contributed to the literature, how much progress we have made in the field of gifted students and what is the current situation in this field. The results will provide us with the opportunity to develop field policies and help us to fill the blank in this area. For this purpose, this study is thought to be a guide in the field of gifted and talented.

Methods: This research aims to investigate 128 doctoral dissertations and master's theses which are made in the field of gifted students and are registered in YÖK (National Thesis Center) database between 1990-2016. The other aim of this study to make a comparative analysis of these theses. This research was designed as qualitative research. Data were analyzed by descriptive analysis technique. Research questions are about the thesis's publication university and department, publication year, its method and subject matter.

Results: According to the results of the research, major universities are the pioneers in publishing these theses. The theses are usually from fields of education, psychology and special education. Quantitative research method is generally used in these theses. The scales improved by others are more used in the theses in the field of gifted. Researchers intensively used BILLSEM as an education institution in their studies. It was observed that studies mainly focus on the primary and secondary school education and are conducted with students as a sample. When we analyze the subject distribution, it is seen that studies on perceptions, awareness, needs and features regarding gifted studies are the most studied subjects.

Discussion and Conclusions: The strategy and implementation plan for gifted individuals (2013) express the lack of differentiated training models and programs as a weakness. It is also emphasized that the number of academic studies including different 
training models is low. Finally, it is seen that there has been a significant increase in the number of master and doctorate theses in the field of gifted in the last three years. Gifted diagnosis and testing, family development programs, scale development and adaptation studies are the least studied subjects. Dağlığlu and Suveren (2013) found that valid and reliable scales of measurement for the determination of gifted in Turkey are not sufficient. Also Cao, Jung \& Lee (2017) found that evaluation of gifted is not enough and it was also found that researches included descriptive statistics based on demographic information. It is thus suggested that in doctorate dissertations and master theses, priority should be given to the needs (recognition, teacher education, programs for gifted and talented etc.) in the field of gifted. Theses about gifted should be studied at different levels of education. Gifted theses should be published in the disciplines other than education and psychology. 


\section{Kaynakça}

Ataman, A. (1998). Üstün zekalılar ve üstün yetenekliler. Eskişehir: Anadolu Üniversitesi Yayınları.

Cao, T. H., Jung, J. Y., \& Lee, J. (2017). Assessment in gifted education: a review of the literature from 2005 to 2016. Journal of Advanced Academics, 28(3), 163-203.

Cevher Kılıç, V. (2015). Türkiye'de üstün ve özel yetenekli çocuklara yönelik bir eğitim politikası oluşturulamaması sorunu üzerine bir değerlendirme. 21. Yüzyllda Ĕ̆itim ve Toplum Ĕ̆itim Bilimleri ve Sosyal Araştırmalar Dergisi, 4(12), 145-154.

Creswell, J. W. (2012). Qualitative inquiry and research design: Choosing among five approaches. Sage publications.

Dağlıoğlu, H., \& Suveren, S. (2013). Okul öncesi dönem üstün yetenekli çocukların belirlenmesinde öğretmen ve aile görüşleri ile çocukların performanslarının tutarlılığının incelenmesi. Kuram ve Uygulamada Ĕ̆itim Bilimleri, 13(1), 431-453.

Dümenci, S. B., Gürsoy, F., \& Aral, N. (2017). Türkiyede okul öncesi dönemdeki üstün potansiyelli ve üstün zekâlı olan çocukların eğitimleri. Kastamonu Eğitim Dergisi, 24(5), 2469-2480.

Farrall, J., \& Henderson, L. (2015). Supporting your gifted and talented child's achievement and well-being: A resource for parents. 12 ocak 2017 tarihinde http://www.ais.sa.edu.au/_files/f/201292/2014\%20Parent\%20Booklet\%20May\%2 03.pdf adresinden erişilmiştir.

Fraenkel, J. R., Wallen, N. E., \& Hyun, H. H. (2012). How to design and evaluate research in education. New York: McGraw-Hill.

Freeman, J. (1998) Educating the very able: Current international research. London: The Stationery Office.

Freeman, J. (2004). Teaching the gifted and talented. Education Today, 54, 17- 21.

Gardner, H. (2011). Frames of mind: The theory of multiple intelligences. Basic books.

Gross, M. U. (1999). Small poppies: Highly gifted children in the early years. Roeper Review, 21(3), 207-214.

Güçin, G., (2014). Türkiye'de üstün yetenekliler ve üstün zekâlılar alanında yapılmış akademik çalışmaların çeşitli değişkenler açısından değerlendirilmesi (Yayınlanmamış yüksek lisans tezi). Sosyal Bilimler Enstitüsü, Yıldız Teknik Üniversitesi, İstanbul.

Heller, K. A. (2004). Identification of gifted and talented students. Psychology Science, 46(3), 302-323.

Hertzog, N. B. (2017). Designing the learning context in school for talent development. Gifted Child Quarterly, 61(3), 219-228.

Hodge, K., (2013). Gifted and talented education. ACT Government. Education and Training. 08/05/2017 tarihinde http://www.det.act.gov.au/_data/assets/pdf_file/0007/587311/Identification2. PDF adresinden erişilmiştir.

Kettler, T., Oveross, M. E., \& Salman, R. C. (2017). Preschool gifted education: perceived challenges associated with program development. Gifted Child Quarterly, 61(2), 117-132. 
Levent, F. (2011). Üstün yetenekli çocukların hakları. İstanbul: Çocuk Vakfi Yayınları.

Marland, S. P. (1972). Education of gifted and talented. Washington D.C. : US Office Education.

Metin, N., \& Kangal, S. B. (2012). Bilim Sanat merkezlerine devam eden 12-14 yaş grubu üstün yetenekli çocukların benlik algılarının incelenmesi. Eğitim ve Bilim, 37(163), 3-16.

Metin, N., Özbay, Y., \& Dağlığlu, E. (2008, June). A preliminary report on the project of identification and education of gifted and talented children in preschool. In 2nd International Conference on Special Education Abstract Book (p. 114), Marmaris, Turkey.

MEB Özel Eğitim ve Rehberlik Hizmetleri Genel Müdürlüğü (2009). Özel Eğitim Hizmetleri Yönetmeliği. $\quad 10.05 .2017 \quad$ tarihinde https://orgm.meb.gov.tr/meb_iys_dosyalar/2012_10/10111226_ozel_egitim_hizmet leri_yonetmeligi_son.pdf adresinden erişilmiştir.

MEB Özel Eğitim ve Rehberlik Hizmetleri Genel Müdürlüğü (2013). Üstün yetenekli bireyler strateji ve uygulama planı (2013-2017). 10.05.2017 tarihinde http://www.tubitak.gov.tr/sites/default/files/10_ek- 1_ustunyetenekliler.pdf adresinden erişilmiştir.

Nacar, S., (2015). 2005-2014 yılları arasında üstün yeteneklilerin matematik eğitimi üzerine yapılan çalışmalar (Yayınlanmamış yüksek lisans tezi). Eğitim Bilimleri Enstitüsü, İnönü Üniversitesi, Malatya.

Özenç, M. \& Özenç, E. G. (2013). Türkiye'de üstün yetenekli öğrencilerle ilgili yapılan lisansüstü eğitim tezlerinin çok boyutlu olarak incelenmesi. [Multidimensional examination of post-graduate theses on gifted students in Turkey]. Türkiye Sosyal Araştırmalar Dergisi, 171, 13-28.

Renzulli, J.S. (1986). The three-ring conception of giftedness: A developmental model for creative productivity. In R.J. Sternberg \& J.E. Davidson (Eds.), Conceptions of giftedness (67-69). Cambridge: Cambridge University Press.

Sak, U. (2011). Üstün yetenekliler eğitim programları modeli (ÜYEP) ve sosyal geçerliği. Eğitim ve Bilim, 36(161), 213-229.

Sak, U., Ayas, M. B., Sezerel, B. B., Öpengin, E., Özdemir, N. N., \& Gürbüz, S. D. (2015). Türkiye'de üstün yeteneklilerin eğitiminin eleştirel bir değerlendirmesi. Türk Üstün Zekâ ve Eğitim Dergisi, 5(2), 110-132.

Smutny, J. F., Walker, S. Y., \& Meckstroth, E. A. (2000). Teaching young gifted children in the regular classroom. Arlington: The Council for Exceptional Children Press.

Subotnik, R. F., Olszewski-Kubilius, P., \& Worrell, F. C. (2011). Rethinking giftedness and gifted education: A proposed direction forward based on psychological science. Psychological Science In The Public Interest, 12(1), 3-54.

Şimşek, H., \& Yıldırım, A. (2011). Sosyal bilimlerde nitel araştırma yöntemleri. Ankara: Seçkin Yayıncılık.

Tavşanc1l, E. \& Aslan, E. (2001). Sözel, yazılı ve diğer materyaller için içerik analizi ve uygulama örnekleri. Epsilon Yayınları: İstanbul 
Terman, L. M. (1921). Intelligence and its measurement. Journal of Educational Psychology, 12(3), 127-133.

Thurstone, L. L. (2013). The nature of intelligence. Routledge.

VanTassel-Baska, J. (1986). Effective curriculum and instructional models for talented students. Gifted Child Quarterly, 30(4), 164-169.

Watters, J. J., \& Diezman, C. M. (2003). The gifted student in science: Fulfilling potential. Australian Science Teachers Journal, 49(3), 46-53. 